\title{
Neuroticismo, expresiones emocionales y percepción de la violencia en escolares
}

\section{Nelly Ugarriza}

Universidad de Lima Lima, Perú

La violencia juvenil expresada a través de pandillas escolares es un problema social que se ha extendido en nuestro país durante esta década. Este fenómeno es estudiado en una muestra de 962 adolescentes varones que asisten a colegios estatales considerados territorios de las principales pandillas escolares de Lima. Se administraron diversas escalas cuya validez y confiabilidad fue establecida en estudios previos y en el presente. A través del análisis multivariable y mediante la $T$ de Hottelling se ha podido apreciar que pertenecer a pandillas escolares y el neuroticismo afectan directamente las expresiones emocionales vitales y la percepción de la violencia. Así mismo, el análisis univariable derivado del MANOVA reveló que el neuroticismo influye sobre las expresiones de cólerahostilidad, ansiedad rasgo-estado, y apreciación de la violencia.

pandillas escolares / neuroticismo /

expresiones emocionales vitales / percepción de la violencia

\section{Neuroticism, vital emotional expressions and perception of violence in youngsters students}

Youth violence as expressed in student gangs, is a social problem that has spread throughout our country during this decade. The phenomenon is analyzed in a sample of 962 male students from public schools that are considered the territories of the main youth gangs in Lima. Diverse tests were applied with proven empirical validity and reliability in previous studies as well as in the present one.

Multivariate analysis of variance and T of Hottelling showed that to be a member of a youth gang and the neuroticism factor directly affect the expression of vital emotions and the perception of violence as a whole. Likewise, the univariate analysis derived from MANOVA confirmed that neuroticism influences the expression of anger-hostility, state-trait anxiety, and the perception of violence. 
El fenómeno de las pandillas juveniles es una de las diversas formas de manifestación de la violencia en el ámbito mundial, que afectan a la sociedad, y constituye uno de los problemas que mayor interés ha concitado entre los investigadores de diferentes disciplinas, tanto nacionales como extranjeros, por sus graves repercusiones en los aspectos social, médico, psicológico, ético y jurídico. Como se sabe, existe una pluralidad de causas explicativas derivadas de observaciones y apreciaciones empíricas, o bien de teorías que no se sustentan en estudios que den cuenta de hallazgos obtenidos con el rigor científico suficiente.

Se parte de la aceptación de que el fenómeno de la violencia juvenil puede ser explicado desde diversos aspectos, convirtiendo su esclarecimiento en algo complejo. Así algunos investigadores ponen énfasis en factores biológicos, como los genes y los cromosomas, y otros lo hacen en características adquiridas, como la personalidad agresiva. Las teorías psicosociales examinan la interacción de la persona con su medio social, localizando la fuente de las manifestaciones de violencia en las frustraciones personales derivadas de relaciones defectuosas y de procesos de aprendizaje que reflejan las actitudes y comportamientos de modelos inadecuados. Otros enfoques de carácter sociocultural, como señala Ponce (1994), examinan las estructuras socioculturales como las normas, los valo- res, la organización institucional o la operación de los sistemas para explicar la violencia. Por último, otra explicación pone énfasis en el desarrollo limitado de la personalidad y de la estructura del carácter como factores de riesgo psicológico al que están expuestos los niños y los jóvenes que se han desarrollado en el seno de hogares resquebrajados y que estudian en colegios cuya organización y dinámica interna día tras día van perdiendo consistencia. La escuela (Tong, 1995) se ha convertido en una institución débil para configurar imágenes concretas de identidad, ya que ha basado gran parte de sus esfuerzos en enseñar contenidos de conciencia y conocimiento. Además, los valores que tratan de inculcar los maestros son suplantados por los del currículo oculto. Así, en la escuela se forjan líderes que son los estudiantes más fuertes, que se enfrentan física o verbalmente con los demás a modo de desafío. Ellos forman parte de grupos de alumnos discordantes que no están acostumbrados a la forma de control escolar y se les reconoce porque pasean por los corredores en horas de clase, arrojan desperdicios en cualquier lugar, pintan arbitrariamente las paredes, etc., se sienten tentados a ensayar cada vez mayores transgresiones a los límites de las normas de conducta aceptada por las autoridades escolares, de esta manera manifiestan su resistencia a la escuela y demuestran su indiferencia frente a ella. Agredir a un compañero, maltratar el 
carro del profesor o formar parte de pandillas se convierte en atentados mayores, que demuestran la existencia de orientación de valores opuestos a los de la escuela. Dentro de este contexto, no existen motivaciones ni condiciones saludables para la vida escolar. Con frecuencia, la actitud de la escuela es ignorar estos procesos y, en última instancia, recurrir a la represión.

Las pandillas o bandas juveniles están integradas generalmente por grupos de jóvenes que viven en la pobreza y la marginación y que se reúnen para cumplir una finalidad determinada: cometer actos delictivos y participar en acciones en las cuales la violencia es expresada de diversas maneras. Las pandillas brindan a estos jóvenes la seguridad, libertad, confianza, ayuda y comprensión que no encontraron en sus hogares, pues les ofrecen apoyo y se preocupan por sus problemas, satisfaciendo sus necesidades de compañía y de autoafirmación individual. En la pandilla o banda el adolescente consigue lo que venía pretendiendo desde hace tiempo: que lo comprendan, quieran, respeten y consideren como un hombre.

La organización y estructura de una pandilla es mucho más fuerte que cualquier otra organización espontánea de jóvenes. Dentro de ella existe una distribución de roles y funciones que permiten a cada uno manifestar sus aptitudes e intereses particulares, a la vez que realizarse, de acuerdo con sus cua- lidades, dando lugar a una especie de "distribución de roles". En esta distribución todos se aprovechan de todos, siendo el líder la personalidad más fuerte y carismática, el que normalmente más cosas conoce y el más intrépido y audaz en todo momento, sobre todo a la hora de realizar algún acto delictivo, siendo seguido por todos en virtud de su machismo, su astucia y sus habilidades. Las bandas juveniles exigen a sus miembros un alto grado de agresividad, obediencia a sus códigos peculiares, sometimiento a duras pruebas y exigencias de todo tipo.

La pandilla asume las funciones del hogar paterno y si algún miembro se deja convencer por sus padres o profesores para salir de ella y cambiar su vida es señalado como un desertor y en ocasiones es buscado con el fin de castigarlo o llevarlo de nuevo al seno de la pandilla.

El adolescente encuentra muchas compensaciones en la pandilla: descubre la renuncia al interés propio en favor del interés colectivo, el dominio de sí mismo y la exaltación del valor físico y moral. Lamentablemente, estos valores no son volcados en beneficio de la sociedad, más bien, manifiestan frente a ella un espíritu fuertemente individualista y egoísta, elaborando una filosofía peculiar que justifica sus acciones, de modo que niega su responsabilidad directa y personal en los delitos realizados, atribuyéndola a sus padres, a la sociedad y a las instituciones. 
Cuando en el hogar y la escuela se dan acontecimientos dolorosos o desagradables, las personas prefieren escapar de ellos y cuando no pueden evitar los ambientes que causan aversión, es de esperar la agresión. No resulta sorprendente que las tasas de conductas agresivas se encuentren en medios donde abunden los modelos agresivos (Bandura, 1973) donde se considera la agresividad como un atributo muy valioso. Gran parte del aprendizaje social ocurre por observación casual o directa de modelos de la vida real, pero, a su vez, un estilo de conducta puede ser transmitido mediante imágenes y palabras, lo mismo que a través de acciones.

El ambiente fuera del hogar también deja su sello en la moralidad del niño y del adolescente. Los amigos influyen con sus ideas en las aspiraciones, los gustos y los deseos. Los amigos también se constituyen en un modelo de trascendental importancia en la formación moral y suelen ser los primeros maestros.

En un estudio previo (Ugarriza, 1998), realizado en la misma muestra de alumnos $(N=992)$ que asisten a colegios estatales considerados territorios de pandillas escolares, se utilizó un análisis de varianza de una sola vía, para probar la hipótesis de que el tipo de familia -tal como es percibido por el adolescente- y el formar parte de las pandillas escolares, influirían en la expresión de las emociones vitales como cólera-hostilidad y ansiedad, así como también en su apreciación de la violencia familiar. Se encontró que el análisis univariado pudo establecer diferencias significativas al, $05 \%$ para las comparaciones entre los alumnos que manifestaron pertenecer a pandillas escolares y los que no pertenecían a ella, en las variables cólera-estado, cólera-rasgo, cólera-temperamento y en la escala de percepción de violencia; siendo las medias más elevadas para los estudiantes que expresaban pertenecer a una pandilla en comparación con los que dicen no pertenecer a ellas.

En el presente trabajo la autora se propone analizar -además de las variables tipo de familia, pertenencia o no a pandillas escolares- la dimensión estabilidad e inestabilidad (neuroticismo) Eysenck (1971) como rasgo de la personalidad que se presume lo hace al adolescente más proclive a expresar sentimientos de hostilidad-cólera y ansiedad, percibiendo además una mayor violencia en el hogar, en las figuras que representan autoridad y en sus amigos.

En este estudio se han adoptado las dimensiones del comportamiento familiar: cohesión y adaptabilidad del modelo circumplejo de Olson (Olson, Russell \& Sprenkle, 1979; 1980; 1982 y 1983). La cohesión familiar es el vínculo emocional que examina el grado en que los miembros de la familia están separados o conectados a ella. Se distinguen cuatro niveles de cohesión que varían entre desligada (muy baja cohesión), separada 
(baja o moderada), conectada (moderada o alta) y amalgamada (muy alta) (véase figura $\mathrm{N}^{\circ} 1$ ). Se sostiene que los niveles centrales de cohesión (separada y conectada) son los que dan lugar a un óptimo funcionamiento familiar, es decir el ser independientes y también vincularse emocionalmente con los miembros de su familia. En cambio los extremos (desligada o amalgamada) son generalmente vistos como problemáticos.

Cuando los niveles de cohesión son elevados (amalgamados) existe demasiado consenso dentro de la familia y muy poca independencia; hay una extrema cercanía emocional y lealtad. Las personas son muy dependientes entre sí y no se le permite a sus miembros un espacio privado mínimo. La energía de las personas se centraliza en el interior del matrimonio o de la familia y existen pocos amigos e intereses fuera de ella.

En el otro extremo (desligado) los miembros de la familia "actúan por sí mismos", tienen sus propios intereses, no se comprometen o no tienen apego a su hogar.

La relación separada no es tan extrema como la desligada. En ella es importante tener un tiempo o espacio propio, como también algún tiempo para estar unidos y tomar decisiones conjuntas. Se puede tener amigos personales pero también se comparten amistades e intereses.

La adaptabilidad familiar se define como la flexibilidad de un sistema marital o familiar para cambiar su estruc- tura de poder, y afrontar así el estrés situacional ante los nuevos roles y desafíos que se plantean a través del desarrollo. Se distinguen cuatro niveles de adaptabilidad: rígida (muy baja), estructurada (baja a moderada), flexible (moderada) y caótica (muy alta), (véase figura $\mathrm{N}^{\circ} 1$ ).

En el mismo sentido que la cohesión, se presume que los niveles centrales de adaptabilidad (estructurada y flexible) conducen a un mejor funcionamiento marital y familiar, mientras que los extremos (rígido y caótico) son los más problemáticos.

Los matrimonios y las familias pueden ir desde un liderazgo rígido y autoritario, con reglas estrictas y excesivo control, a una relación caótica, errática y sin control. Una relación estructurada es menos rígida y el control se comparte entre los padres. Los roles son más estables y algunas reglas pueden variar. El liderazgo se comparte igualmente. Una relación caótica tiene un liderazgo errático y limitado. Las decisiones son impulsivas y no son producto de la reflexión. Las reglas no son claras y varían de persona a persona.

Basándonos en el modelo circumplejo, los niveles muy altos de cambio (caótico) y niveles muy bajos de cambio (rígido) pueden ser problemáticos para el matrimonio. Más bien, las relaciones estructuradas y flexibles pueden ser capaces de balancear algún cambio y alguna estabilidad de un modo más funcional. 


\section{Ugarriza}
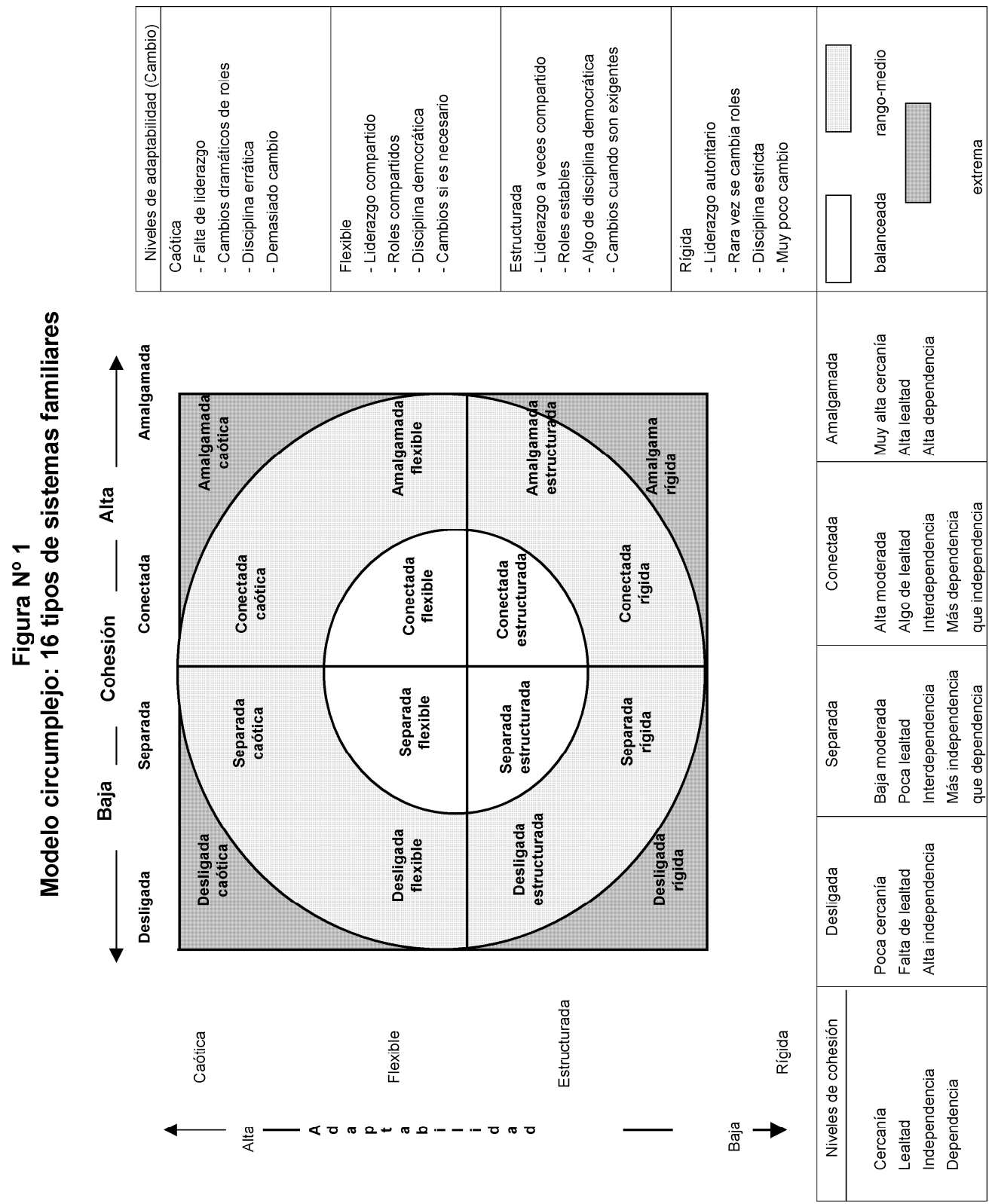
Combinando los diferentes niveles de cohesión y adaptabilidad se obtienen tres tipos de familia: balanceada, rango medio y extrema (véase figura $\mathrm{N}^{\circ} 1$ ).

El tipo de familia balanceada es el adecuado y corresponde a la combinación de familias separada-flexible, conectada-flexible, separada-estructurada y conectada-estructurada.

El tipo de familia rango-medio comprende la combinación de la familia: separada-caótica, desligada-flexible, desligada-estructurada, separada-rígida, conectada-rígida, amalgamada-estructurada, amalgamada-flexible y conectada-caótica.

El tipo de familia extrema se refiere a la combinación de familias desligadacaótica, desligada-rígida, amalgamadarígida y amalgamada-caótica. En el modelo circumplejo la distinción más importante que se debe hacer es entre los tipos de familias balanceadas y las extremas.

Spielberger, Gorsuch y Lushene (1970) distinguen dos tipos de ansiedad: ansiedad-estado y ansiedad-rasgo.

La ansiedad-estado puede variar desde una ligera aprensión hasta un temor intenso o pánico. Así también, un estado de cólera (Spielberger, 1970) consiste en sentimientos que pueden variar desde una ligera irritación o fastidio hasta una rabia intensa y furia.

La ansiedad-rasgo y cólera-rasgo se refieren a las diferencias individuales en cuanto a la frecuencia e intensidad al experimentar estas emociones. Las diferencias individuales en rasgos de ansiedad (AR) son factores que contribuyen a la evaluación cognitiva de amenaza. Así, los individuos con niveles elevados de AR son más propensos a evaluar como más peligrosos los eventos dentro del contexto social que representan amenaza. Además, son más vulnerables a sentirse criticados por otros, debido a que tienen una pobre autoestima, falta de autoconfianza $y$ temor al fracaso.

El ambiente familiar, socioeconómico y cultural puede ser percibido como una amenaza (evaluación cognitiva) dando lugar a reacciones emocionales de ansiedad y cólera-estado, que podrían conducir a desarrollar conductas desadaptativas, formar parte de pandillas, presentar bajo rendimiento académico, trastornos somáticos, entre otros, dependiendo de la estructura de personalidad de los adolescentes.

Por otro lado, al involucrarse con estos grupos de pandilleros, si bien les genera seguridad, confianza y sentido de pertenencia, la amenaza de estar fuera de ellos (evaluación cognitiva) les causa reacciones emocionales adversas que afectan su salud y su bienestar psicológico, haciéndolos más vulnerables a manifestar conductas desadaptativas que los induce a cometer actos delictivos, acatando las normas del grupo, las mismas que se encuentran al margen de cualquier consideración ética. La pandilla se constituye así en un paradigma, y sus "líderes" se con- 
vierten en modelos a quienes hay que seguir y acatar, porque de lo contrario los adolescentes sienten que pierden su identidad de grupo.

Aquí se utiliza el procedimiento estadístico del análisis multivariable, porque los fenómenos que se desean explicar son de naturaleza compleja. Una diversidad de variables influyen sobre el comportamiento y los métodos multivariables son formas de estudiar las múltiples influencias de algunas variables independientes sobre una o más variables dependientes. Para Kerlinger (1988), los métodos multivariables, retratan la compleja "realidad" del comportamiento, y es obvio que los métodos multivariables son muy convenientes para probar formulaciones teóricas muy complejas, puesto que su misma naturaleza es el análisis de diversas variables a la vez, ya que, por definición, las teorías son conjuntos interrelacionados de constructos o variables.

Basándonos en lo expuesto, el objetivo principal del presente estudio es examinar en qué medida es posible adoptar un modelo explicativo que exprese las relaciones múltiples que pueden existir entre las variables independientes: tipo de familia, pertenencia o no a pandillas escolares y neuroticismo, que se presume afectan directamente las expresiones emocionales vitales (cólera-hostilidad y ansiedad) y la percepción de la violencia tomadas en su conjunto de un grupo de jóvenes de colegios estatales en situación de alto riesgo.

\section{MÉTODO}

\section{Universo o población}

De 15 centros educativos considerados "territorio" de las principales pandillas escolares, según los datos proporcionados por el Ministerio de Educación (El Comercio, 1996), sólo se tuvieron en cuenta 13 colegios pertenecientes a los distritos de Lima Metropolitana. En el caso de los distritos que tenían dos colegios representativos se eligió uno de ellos al azar, conformándose el universo tal como se muestra en la tabla $\mathrm{N}^{\circ} 1$. El universo de estudio estuvo integrado por 9.196 alumnos varones de colegios estatales de Lima Metropolitana, que cursaban tercero, cuarto y quinto de secundaria. Sus edades estaban comprendidas entre los 14 y 19 años.

\section{Muestra}

Para seleccionar la muestra se utilizó la fórmula para población finita con un margen de error del $95 \%$ y un nivel de confianza de $2,58 \%$. Luego de aplicar la fórmula de corrección se determinó que 355 alumnos constituirían el tamaño de la muestra. Sin embargo, se decidió encuestar a 962 adolescentes cuyas frecuencias y distribución porcentual aparece en la tabla $\mathrm{N}^{\circ} 2$.

Se visitaron los colegios solicitándose información sobre el número de secciones correspondientes a tercero, cuarto y quinto año de secundaria. Luego, sobre la base del listado del número de sec- 
Tabla № 1

Colegios seleccionados para la investigación

\begin{tabular}{llrrrrr}
\hline \multicolumn{1}{c}{ Colegio } & Distrito & $3^{\circ}$ & $4^{\circ}$ & $5^{\circ}$ & $\begin{array}{c}\mathrm{N}^{\circ} \text { de } \\
\text { alumnos }\end{array}$ & USE \\
\hline 1. José Granda & San Martín de Porres & 216 & 225 & 203 & 644 & 02 \\
2. Ricardo Bentín & Rímac & 230 & 313 & 282 & 825 & 02 \\
3. Bartolomé Herrera & San Miguel & 234 & 247 & 228 & 709 & 03 \\
4. Ricardo Palma & Surquillo & 108 & 138 & 220 & 466 & 07 \\
5. Ntra. Señora de Guadalupe & Cercado & 664 & 759 & 653 & 2.076 & 03 \\
6. Pedro Labarthe & La Victoria & 305 & 330 & 257 & 892 & 00 \\
7. Melitón Carbajal & Lince & 382 & 480 & 450 & 1.312 & 03 \\
8. Alfonso Ugarte & San Isidro & 371 & 400 & 356 & 1.127 & 03 \\
9. Federico Villarreal & Miraflores & 212 & 198 & 169 & 579 & 07 \\
10. José María Eguren & Barranco & 163 & 205 & 118 & 566 & 07 \\
\hline TOTAL & & 2.885 & 3.295 & 3.016 & 9.196 & \\
\hline
\end{tabular}

ciones por grado de cada colegio, se eligió al azar una sección para ser encuestada, excepto en los colegios Nuestra Señora de Guadalupe y Bartolomé Herrera, en los que se aplicaron los cuestionarios a tres secciones más, en el primer caso por ser el colegio de mayor población estudiantil y en el segun- do por su cercanía a la Provincia Constitucional del Callao.

\section{Mediciones}

Para la medición de las diferentes variables se emplearon las escalas de cohesión y adaptabilidad familiar de Olson, el inventario de la expresión de

Tabla № 2

Frecuencias absolutas y distribución porcentual de la muestra $(n=992)$ por colegio de procedencia

\begin{tabular}{lrr}
\hline Centros educativos & $\mathrm{f}$ & $\%$ \\
\hline 1. José Granda & 66 & 6,9 \\
2. Ricardo Bentín & 82 & 8,5 \\
3. Bartolomé Herrera & 145 & 15,1 \\
4. Ricardo Palma & 72 & 7,5 \\
5. Nuestra Señora de Guadalupe & 175 & 18,2 \\
6. Pedro Labarthe & 73 & 7,6 \\
7. Melitón Carbajal & 70 & 7,3 \\
8. Alfonso Ugarte & 94 & 9,8 \\
9. Federico Villarreal & 86 & 8,9 \\
10. José María Eguren & 99 & 10,2 \\
\hline Total & 962 & 100,0
\end{tabular}


cólera-hostilidad, el inventario de ansiedad rasgo-estado, la escala de percepción de la violencia, y el inventario de personalidad de Eysenck.

Las escalas de cohesión y adaptabilidad familiar han sido utilizadas para evaluar estas dos dimensiones del modelo circumplejo, formulado por Olson y sus colegas. El modelo permite que una persona clasifique a las familias en 16 tipos específicos o en tres grupos más generales que corresponden a familias balanceadas, de rango medio y familias extremas.

Las escalas se basan en los ítems de las escalas de evaluación de la adaptabilidad y cohesión familiar-Faces II (doce reactivos se repiten en Faces III). La escala tiene 20 ítems, 10 evalúan cohesión y 10 adaptabilidad, fueron diseñadas con fines de investigación, evaluación clínica y para obtener una "perspectiva del interior" del funcionamiento familiar, tal como es percibido por diversos miembros de la familia.

Dentro de la dimensión de cohesión hay dos ítems relativos a cada uno de los siguientes aspectos: vinculación emocional, límites familiares, coalición, tiempo, espacio, amigos, toma de decisiones e intereses y recreación. Para la adaptabilidad hay dos ítems para cada uno de los conceptos de liderazgo y control, disciplina, roles y reglas y tres para asertividad y negociación.

El inventario de la expresión de cólera-hostilidad (IECH) brinda una medición concisa del modo como se experi- menta y expresa la cólera, utilizándose como un método para medir los componentes de la cólera que evalúan aspectos de la personalidad normal y anormal.

El inventario consta de 44 ítems distribuidos en seis escalas: cólera estado (CE), contiene 10 ítems que examinan los sentimientos de cólera en un momento dado, es decir estar con cólera; cólera rasgo (CR), comprende diez ítems, que miden las diferencias individuales en la disposición a experimentar cólera; cólera manifiesta (CM), seis ítems referidos a la frecuencia con que un individuo manifiesta su cólera hacia otra persona u objeto del medio ambiente; cólera contenida (CC), seis ítems que evalúan cuán a menudo los sentimientos de cólera son reprimidos o suprimidos; control de la cólera manifiesta (CCM), seis ítems que expresan la frecuencia con que una persona intenta controlar la expresión de la cólera conductualmente y control de la cólera contenida (CCC), mide la frecuencia con que un individuo intenta suprimir la expresión de cólera cognitivamente.

El inventario de ansiedad rasgo-estado (Idare) fue construido por Spielberger, Gorsuch y Lushene en 1970, con el propósito de ofrecer una escala relativamente breve y confiable para medir rasgos y estados de ansiedad. Comprende dos escalas separadas de autoevaluación que miden conceptos diferentes de la ansiedad: estado (E) y ras- 
go (R). La distinción de rasgo-estado (ser y estar) dentro del campo de la ansiedad ha sido validada posteriormente en numerosos estudios de investigación (Gaudry, Spielberger \& Vagg, 1975).

El Idare consta de 40 elementos, los primeros 20 corresponden a la escala de ansiedad-rasgo (AR), que mide la propensión a la ansiedad en la que difieren las personas en su tendencia a percibir las situaciones como amenazadoras y a elevar, consecuentemente, su ansiedad estado. Los 20 ítems siguientes se refieren a ansiedad-estado $(A E)$, que evalúa un estado o condición emocional transitoria del organismo humano, que se caracteriza por sentimientos subjetivos, conscientemente percibidos de tensión y aprehensión. Así como una hiperactividad del sistema autonómico. Puede variar con el tiempo y fluctuar en su intensidad.

La escala ansiedad-rasgo (AR) puede ser utilizada en la investigación para seleccionar sujetos con diferente predisposición a responder al estrés psicológico con distintos niveles de ansiedad; y la escala ansiedad-estado (AE) para determinar los niveles actuales de intensidad de la ansiedad inducidos por procedimientos experimentales cargados de tensión o como índice del nivel del impulso.

La escala de percepción de la violencia (EPV) fue elaborada para el estudio sobre farmacodependencia en grupos vulnerables (Ugarriza \& Villanueva,
1990), validada en un estudio posterior sobre tipo de familia y comunicación de los adolescentes con sus padres (Ugarriza, 1995) y ha sido empleada en este estudio con algunas modificaciones. $\mathrm{La}$ escala de percepción de la violencia comprende 20 reactivos que indagan sobre la agresión física o verbal entre los miembros de la familia y frente a las figuras que representan la autoridad, y entre los coetáneos.

Además, en esta encuesta se han incluido tres ítems para indagar si el adolescente manifiesta pertenecer o no a una "mancha", si cuando está en el grupo busca peleas a otros y por qué razones pelean. Las respuestas a estos tres reactivos han sido tomados como criterios para constituir los grupos de alumnos que dicen pertenecer o no a las denominadas pandillas o manchas.

El inventario de personalidad de Eysenck $(E P I)$ es un instrumento autodescriptivo de la personalidad que ha sido trabajado a partir del análisis factorial y siguiendo la teoría jerárquica de la personalidad de Eysenck. En este estudio se ha utilizado la forma A, estandarizada en Lima por Anicama (1974) -en una muestra de 2.000 personas, entre ejecutivos y profesionales, estudiantes empleados y obreros- pero los ítems han sido adaptados por Ugarriza y Palma (1997), elaborándose una nueva versión "forma adolescentes", para ser utilizados en alumnos de secundaria.

El inventario está constituido por tres escalas: escala $\mathrm{E}$ (dimensión extrover- 
sión-introversión), escala N (dimensión estabilidad-inestabilidad) y escala L (escala de mentiras). La escala completa (forma adolescentes) consta de 53 ítems que son declaraciones formuladas en términos de preguntas para ser contestadas en forma negativa o afirmativa.

Para fines del estudio sólo se ha empleado la escala $\mathrm{N}$, neuroticismo (dimensión estabilidad-inestabilidad), que considera los siguientes rasgos:

- Rasgos de tipo estable. Expresan una adecuada organización de la personalidad, buen control de las emociones y tolerancia a la frustración. La persona es capaz de valerse por sus propios medios y actúa de modo independiente. Posee un variado repertorio de intereses, tiene una valoración más o menos adecuada de su potencial real de eficiencia, flexible en el enfoque de situaciones distintas, es capaz de una autocrítica objetiva, siendo calmada, espontánea en sus relaciones con los demás.

- Rasgos de tipo inestable. Revelan una inadecuada organización de la personalidad, poca tolerancia a la frustración. La persona es dependiente de los demás, muy sugestionable, denota un estrecho margen de intereses, es muy rígida en sus relaciones interpersonales, inquieta, irritable y presenta dificultades para el aprendizaje a ritmo rápido.
En la calificación se consideró un punto por cada respuesta que coincidía con la clave, el total máximo que se puede alcanzar en la escala $\mathrm{N}$ es 24 puntos y el mínimo 0 puntos, teniéndose en cuenta que un puntaje mayor de cuatro en la escala $\mathrm{L}$ anula la prueba.

En general, los ítems de los diferentes instrumentos empleados han sido redactados para ser comprendidos desde los 12 años, utilizándose frases cortas y simples que podrían ser entendidas hasta por personas con limitaciones en su habilidad lectora.

En cuanto a la calificación de las cuatro primeras escalas, en este estudio se han modificado los valores originales asignados a cada ítem con la finalidad de que el examinado, dadas sus características cognoscitivas, discrimine más fácilmente entre las graduaciones de las respuestas dadas a los diferentes reactivos. Por esta razón cada ítem se puntúa en una escala de uno a tres en el caso de ser positivo y el sentido inverso si es negativo y no como era originalmente.

El puntaje directo alcanzado en cada escala se obtiene por la sumatoria de los ítems marcados en las escalas y subescalas correspondientes. La administración y calificación pueden ser realizadas de modo individual o en pequeños grupos, por personas que no necesitan un entrenamiento profesional en psicología u otra profesión afín.

Pero la interpretación de los puntajes alcanzados en las distintas escalas 
requiere una certificación profesional en psicología o psiquiatría, con conocimientos de psicometría. Las instrucciones generales para responder al IECH y el registro de datos sobre información demográfica aparecen en la parte superior de la prueba.

La presente edición del inventario de las escalas es considerada sólo con propósitos de investigación y el análisis estadístico fue llevado a cabo con los puntajes directos (raw scores).

Las personas que intenten utilizar estas pruebas psicológicas con propósitos clínicos deberán desarrollar sus propias normas (percentiles y puntuaciones $\mathrm{T}$ normalizadas en cada caso) con la finalidad de realizar interpretaciones más detalladas.

\section{VALIDEZ Y CONFIABILIDAD DE LOS INSTRUMENTOS DE RECOLECCIÓN DE DATOS}

La validez de construcción se estableció mediante el método intrapruebas, habiéndose determinado para los datos del presente estudio, la homogeneidad de las escalas de cohesión y adaptabilidad familiar, del inventario de cólerahostilidad, del inventario de ansiedad rasgo-estado, de la escala de percepción de la violencia, y de la escala de neuroticismo de Eysenck.

Según Brown (1980), las medidas de la homogeneidad son índices de la consistencia interna de las mediciones psicológicas y expresan el grado en que los reactivos de las pruebas se interco- rrelacionan. La homogeneidad, sobre todo en su relación con la definición de las mediciones psicológicas, constituye un aspecto importante de la validez. En un sentido, la homogeneidad se encuentra entre la confiabilidad y la validez.

Como se muestra en la tabla $\mathrm{N}^{\circ} 3$, los coeficientes alfa de Cronbach para los diferentes instrumentos de medición fueron estadísticamente significativos, encontrándose por encima de .60. Los coeficientes alfa obtenidos para la escala de adaptabilidad fue $.6491 \mathrm{y}$ para cohesión de .7224. La escala de percepción de la violencia expresa un coeficiente alfa de .7399 y la de neuroticismo de .7524. En el IECH los coeficientes alfa varían de .4734 a .8559 . Los más bajos son para las áreas de cólera-manifiesta (.4734) y cólera-contenida (.5178) y los más altos corresponden a cólera-estado (.8559) y control de la cólera manifiesta (.7608). En general, los reactivos de las diferentes áreas del IECH se intercorrelacionan de modo significativo. Los coeficientes alfa para el inventario de ansiedad-rasgo y ansiedad-estado son también elevados y significativos: .8068 y .7484 respectivamente.

En la tabla $N^{\circ} 4$ aparecen los porcentajes de ítems que quedan por ser confiables, indicándose además los reactivos que se descartan por no alcanzar el nivel de significación por encima de .20. En adaptabilidad se eliminan los reactivos que evalúan asertividad y re- 





glas y en cohesión los que examinan si los miembros de la familia comparten entre sí o se evitan. En neuroticismo se eliminan los que indagan por enfadarse y por no necesitar comunicarse con otros cuando están fastidiados y el po- nerse nervioso frente a determinadas situaciones. En el IECH se descartan sólo dos ítems vinculados a cólera manifiesta y cólera contenida. En la escala de ansiedad-rasgo se elimina el ítem que se vincula con sentir ansiedad y en

Tabla № 4

Relación de ítems eliminados por no alcanzar un coeficiente alfa significativo y porcentaje de ítems retenidos en cada escala

\begin{tabular}{ccc}
\hline & $\mathrm{N}^{\circ}$ de & ítems que se descartan \\
Tests o escalas & ítems & dems \\
de cada & prueba & \\
& & \\
\hline
\end{tabular}

COH-ADAP-

(OLSON)

Cohesión

Adaptabilidad

Personalidad

Neuroticismo

(Eysenck)

24

\section{IECH}

CE

CR

CM

CC

$\mathrm{CCC}$

CCM

Ansiedad

AR

AE

16
(34) Los miembros de mi familia se evitan entre sí (espacio).

(38) Los miembros de mi familia prefieren formar grupos pequeños para hacerlo todo juntos (evaluaciones)

(23) Los miembros de mi familia dicen lo que ellos quieren (asertividad).

(33) Es difícil lograr que cambie una regla en nuestra familia (reglas).

(37) Los miembros de mi familia temen decir lo que ellos quieran (asertividad).

(07) ¿Te enfadas a veces?

(28) Cuando te fastidias, necesitas de algún(a) amigo(a) para hablar con él (ello).

(43) ¿Te pones nervioso en lugares como ascensores, trenes o túneles?

(68) Generalmente... guardo el rencor y no se lo digo a nadie.

(74) Generalmente... si alguien me molesta, le digo cómo me siento.

83

(92) Me siento ansioso(a).

(109) Me siento descansado(a).

(114) Tomo las cosas muy a pecho. 
ansiedad-estado, se excluye el sentirse descansado, tomar las cosas muy a pecho y evadir dificultades. En la escala de percepción de la violencia sólo se elimina el responder con tranquilidad cuando se pelea.

El escaso número de ítems eliminados por no ser significativos en cada una de las escalas revela la homogeneidad de los diferentes constructos evaluados. Por razones de espacio no se reportan los datos correspondientes al promedio y la varianza de cada escala si el ítem se elimina, la correlación ítem-total y el coeficiente alfa si el ítem se elimina.

Respecto de las escalas de adaptación y cohesión familiar, el autor reporta la validez de construcción de la escala mediante un análisis de factores con el objetivo de mantener la independencia de los mismos, habiéndose encontrado la misma estructura factorial y ninguna correlación entre las dimensiones de cohesión y adaptabilidad $(\mathrm{r}=.03)(\mathrm{Ol}-$ son et al., 1983). Otra indicación de la validez teórica de las dos escalas es la alta correlación de los ítems dentro de cada subescala con la escala total (Olson et al., 1983). Con respecto a la confiabilidad, los coeficientes de consistencia interna son .77 para cohesión, .62 para adaptabilidad y .68 para la escala completa.

Un estudio sobre normalización del inventario de la expresión cólera-hostilidad (Ugarriza, 1997), en una muestra de 1.502 estudiantes del nivel ini- cial de una universidad estatal y otra privada de la ciudad de Lima, determinó la validez de construcción del IECH mediante la técnica intrapruebas. Los coeficientes alfa de Cronbach revelaron la consistencia interna de las escalas que se administraron: expresión de cólera-hostilidad (IECH), ansiedad rasgo-estado (Idare) y depresión (IDB). Las correlaciones entre las variables cólera-hostilidad y ansiedad rasgo-estado fueron estadísticamente significativas. El análisis factorial de las correlaciones entre las 11 variables examinadas permitieron encontrar, mediante la rotación Varimax, tres factores: factor I, en el que convergen cólera-rasgo, cólera-contenida y cólera-manifiesta (cargas factoriales a .53). Factor II que establece relación de convergencia entre cólera-estado, ansiedad-rasgo y ansiedad-estado (cargas factoriales .59); y factor III que relaciona la cólera expresada conductual y cognitivamente (cargas factoriales a .80).

En el Perú, Anicama (1974) estudió la validez del inventario de Eysenck mediante dos procedimientos:

- El método de los grupos nominados, por el cual se estableció relaciones entre los puntajes del cuestionario y los criterios de jueces independientes. Estos resultados indicaron una relación significativa entre el criterio del juez (cómo él calificaba al sujeto) y el puntaje obtenido por el sujeto en el test.

- El segundo procedimiento fue el "método de validez clínica", por 
medio del cual se buscó relacionar los diagnósticos clínicos de patología de la conducta con los puntajes obtenidos en los cuestionarios. Las puntuaciones revelan una relación altamente significativa entre el diagnóstico clínico y el EPI-B, lo que se encontraba de acuerdo con el esquema teórico de Eysenck.

\section{RESUlTADOS}

Para realizar el análisis multivariable ha sido necesario, primero, determinar la frecuencia de alumnos y su distribución porcentual, dentro de cada una de las variables independientes consideradas en una muestra de alumnos que asisten a colegios identificados como territorio de pandillas escolares.
En la tabla $\mathrm{N}^{\mathrm{o}} 5$ se aprecia que la percepción de la estructura familiar del adolescente de una muestra $\mathrm{N}=962$, es de $51,4 \%$ como tipo balanceada; $34,2 \%$, rango medio y el $14,4 \%$ como extrema. Este hallazgo es importante, porque si sumamos estas dos últimas categorías el 48,6\% representarían familias que al ser calificadas por sus hijos como malfuncionantes, los coloca en condición de alto riesgo de presentar conductas inadecuadas.

Así mismo se observa que el 47,7\% $(\mathrm{N}=962)$ manifiesta pertenecer a pandillas escolares o "manchas". Cuando se clasifica la muestra según la dimensión estabilidad-inestabilidad emocional (neuroticismo), el $14,9 \%$ son altamente inestables, el 38,3\% presentan tendencia inestable. Casi el $30 \%$ son estables y el $17 \%$ altamente estables.

Tabla № 5

Distribución porcentual de la muestra $(\mathrm{N}=962)$ según el tipo de familia, pertenencia a pandilla y neuroticismo

\begin{tabular}{|c|c|c|c|}
\hline Variables & & f & $\%$ \\
\hline \multicolumn{4}{|l|}{ Tipo de familia: } \\
\hline Extrema & & 139 & 14,4 \\
\hline Balanceada & & 49 & 51,4 \\
\hline \multirow[t]{2}{*}{ Rango medio } & & 329 & 34,2 \\
\hline & Total & 962 & 100,0 \\
\hline \multicolumn{4}{|c|}{ Pertenencia a pandilla: } \\
\hline Sí & & 459 & 47,7 \\
\hline \multirow[t]{2}{*}{ No } & & 503 & 52,3 \\
\hline & Total & 962 & 100,0 \\
\hline \multicolumn{4}{|l|}{ Neuroticismo: } \\
\hline Altamente inestable & & 143 & 14,9 \\
\hline Tendencia inestable & & 368 & 38,3 \\
\hline Tendencia estable & & 288 & 29,9 \\
\hline \multirow[t]{2}{*}{ Altamente estable } & & 163 & 16,9 \\
\hline & Total & 962 & 100,0 \\
\hline
\end{tabular}




\section{Ugarriza}

Tabla № 6

Tabulación cruzada de tipo de familia, pertenencia a pandilla y neuroticismo

\begin{tabular}{|c|c|c|c|c|c|c|c|c|}
\hline \multirow{2}{*}{$\begin{array}{l}\text { Tipo de } \\
\text { Familia }\end{array}$} & & & & \multicolumn{4}{|c|}{ Neuroticismo } & \multirow[b]{2}{*}{ Total } \\
\hline & & & & $\begin{array}{l}\text { Altamente } \\
\text { inestable }\end{array}$ & $\begin{array}{l}\text { Tendencia } \\
\text { inestable }\end{array}$ & $\begin{array}{c}\text { Tendencia } \\
\text { estable }\end{array}$ & $\begin{array}{l}\text { Altamente } \\
\text { estable }\end{array}$ & \\
\hline \multirow[t]{13}{*}{ Extrema } & $\begin{array}{l}\text { Pertenece a } \\
\text { pandilla }\end{array}$ & Sí & $\begin{array}{l}\mathrm{f} \\
\% \text { dentro }\end{array}$ & 17 & 26 & 25 & 4 & 72 \\
\hline & & & pertenece a pandilla & 23.6 & 36.1 & 34.7 & 5.6 & 100.0 \\
\hline & & & $\%$ dentro Neuroticismo & 60.7 & 50.0 & 58.1 & 25.0 & 51.8 \\
\hline & & & $\%$ Total & 12.2 & 18.7 & 18.0 & 2.9 & 51.8 \\
\hline & & $\mathrm{NO}$ & $f$ & 11 & 26 & 18 & 12 & 67 \\
\hline & & & $\%$ dentro & 16.4 & 38. & 269 & 179 & 1000 \\
\hline & & & $\%$ dentro Neuroticismo & 39.3 & 50.0 & 41.9 & 75.0 & 48.2 \\
\hline & & & $\%$ Total & 7.9 & 18.7 & 12.9 & 8.6 & 48.2 \\
\hline & Total & & $f$ & 28 & 52 & 43 & 16 & 139 \\
\hline & & & $\%$ dentro & & & & & \\
\hline & & & Pertenece a pandilla & 20.1 & 37.4 & 30.9 & 11.5 & 100.0 \\
\hline & & & $\%$ dentro Neuroticismo & 100.0 & 100.0 & 100.0 & 100.0 & 100.0 \\
\hline & & & $\%$ Total & 20.1 & 37.4 & 30.9 & 11.5 & 100.0 \\
\hline \multirow[t]{13}{*}{ Balanceada } & $\begin{array}{l}\text { Pertenece a } \\
\text { pandilla }\end{array}$ & sí & $\begin{array}{l}f \\
\% \text { dentro }\end{array}$ & 32 & 103 & 65 & 29 & 229 \\
\hline & & & Pertenece a pandilla & 14.0 & 45.0 & 28.4 & 12.7 & 100.0 \\
\hline & & & $\%$ dentro Neuroticismo & 53.3 & 52.8 & 42.8 & 33.3 & 46.4 \\
\hline & & & $\%$ Total & 6.5 & 20.9 & 13.2 & 5.9 & 46.4 \\
\hline & & NO & $f$ & 28 & 92 & 87 & 58 & 265 \\
\hline & & & $\%$ dentro & & & & & \\
\hline & & & Pertenece a pandilla & 10.6 & 34.7 & 32.8 & 21.9 & 100.0 \\
\hline & & & $\%$ dentro Neuroticismo & & 47.2 & 57.2 & 66.7 & 53.6 \\
\hline & & & $\%$ Total & 5.7 & 18.6 & 17.6 & 11.7 & 53.6 \\
\hline & Total & & f $\%$ dentro & 60 & 195 & 152 & 87 & 494 \\
\hline & & & Pertenece a pandilla & 12.1 & 39.5 & 30.8 & 17.6 & 100.0 \\
\hline & & & $\%$ dentro Neuroticismo & 100.0 & 100.0 & 100.0 & 100.0 & 100.0 \\
\hline & & & $\%$ Total & 12.1 & 39.5 & 30.8 & 17.6 & 100.0 \\
\hline \multirow[t]{14}{*}{ Rango medio } & Pertenece a & Sí & $f$ & 34 & 61 & 45 & 18 & 158 \\
\hline & & & Pertenece a pandilla & 21.5 & 38.6 & 28.5 & 11.4 & 100.0 \\
\hline & & & $\%$ dentro Neuroticismo & 61.8 & 50.4 & 48.4 & 30.0 & 48.0 \\
\hline & & & $\%$ Total & 10.3 & 18.5 & 13.7 & 5.5 & 48.0 \\
\hline & & NO & $f$ & 21 & 60 & 48 & 42 & 171 \\
\hline & & & $\%$ dentro & & & & & \\
\hline & & & Pertenece a pandilla & 12.3 & 35.1 & 28.1 & 24.6 & 100.0 \\
\hline & & & $\%$ dentro Neuroticismo & 38.2 & 49.6 & 51.6 & 70.0 & 52.0 \\
\hline & & & $\%$ Total & 6.4 & 18.2 & 14.6 & 12.8 & 52.0 \\
\hline & Total & & $f$ & 55 & 121 & 93 & 60 & 329 \\
\hline & & & $\%$ dentro & & & & & \\
\hline & & & Pertenece a pandilla & 16.9 & 36.8 & 28.3 & 18.2 & 100.0 \\
\hline & & & $\%$ dentro Neuroticismo & 100.0 & 100.0 & 100.0 & 100.0 & 100.0 \\
\hline & & & $\%$ Total & 16.7 & 36.8 & 28.3 & 18.2 & 100.0 \\
\hline
\end{tabular}


En la tabla $\mathrm{N}^{\circ} 6$ se presentan las frecuencias absolutas y la distribución porcentual de la tabulación cruzada del tipo de familia, pertenencia a pandilla y neuroticismo, observándose que el $23,6 \%$ del grupo que pertenece a pandillas $(\mathrm{N}=72)$, son altamente inestables y perciben a su familia como extremas. En el grupo que evalúa a su familia como balanceada $(\mathrm{N}=229)$ el $14 \%$ pertenece a pandillas escolares y son altamente inestables (neuróticos). En el grupo considerado de rango medio $(\mathrm{N}=$ 158 ) el $21,5 \%$ también manifiesta formar parte de pandillas y ser además altamente inestables.

En los histogramas (véanse figuras $\mathrm{N}^{\circ}$ 2, 3 y 4) se aprecia con mayor claridad la distribución por frecuencias de la tabulación cruzada que relacionan las variables. Así, en el tipo de familia extrema, existe una mayor frecuencia de alumnos que son neuróticos y pertene- cen a pandillas; lo mismo ocurre en el grupo que ve a su familia como rango medio y en el grupo que percibe a su familia como balanceada (adecuada). Esto sugiere una mayor inestabilidad en los adolescentes que pertenecen a pandillas independientemente de la percepción que tengan del funcionamiento familiar.

En esta primera fase se ha descrito cómo se distribuyen los alumnos considerando la tabulación cruzada de las variables: familia, pertenencia a pandillas y neuroticismo, en términos de su frecuencia. En la segunda fase, el análisis está más enfocado al estudio de las relaciones múltiples expresadas gráficamente en la figura $\mathrm{N}^{\circ} 5$ mediante un "diagrama de trayectoria" en el cual se utiliza $\mathrm{X}_{1}, \mathrm{X}_{2} \mathrm{y} \mathrm{X}_{3}$ para simbolizar las variables independientes que afectan de modo directo a la(s) variable(s) dependiente(s). A esto se denomina problema directo de regresión múltiple

Figura № 2

Tipo de familia extrema






\section{Ugarriza}

Figura № 3

Tipo de familia balanceada

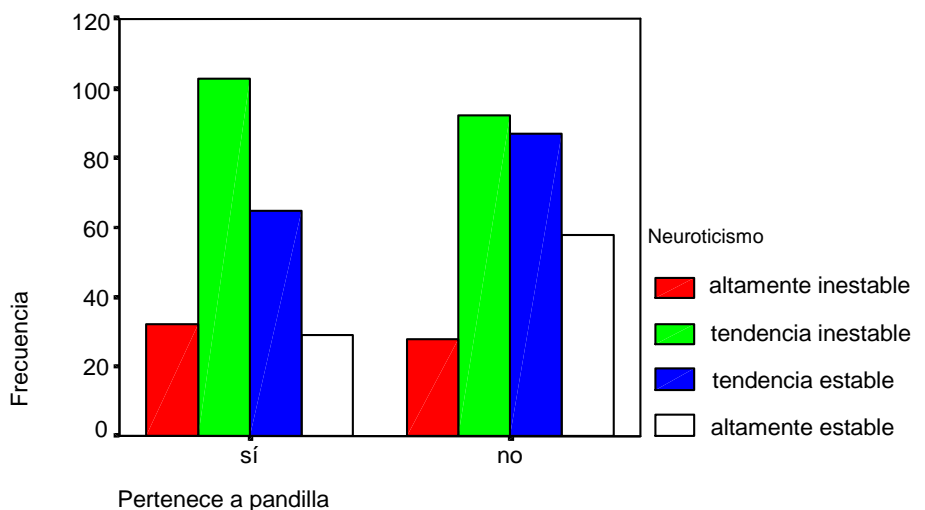

Figura № 4

Tipo de familia rango media



Pertenece a pandilla

(Kerlinger, 1994) en el cual K (=3) variables influyen mutua y simultáneamente sobre una variable dependiente (vista en su conjunto).

El problema consiste en encontrar la relación entre las tres variables independientes tomadas en forma simultánea y la variable dependiente para luego determinar qué tanto influye cada una de las variables independientes $X_{1}$, $\mathrm{X}_{2} \mathrm{y}_{3}$ en la variable dependiente $\mathrm{Y}$.
En la tabla $\mathrm{N}^{\mathrm{o}} 7$ se aprecian los datos correspondientes al análisis multivariable (MANOVA) mediante la T de Hottelling. En ella es factible analizar los efectos de tres variables: familia $\mathrm{x}$ pertenencia a pandillas $\mathrm{x}$ neuroticismo (variables independientes o criterio) y su interacción sobre el conjunto de expresiones emocionales (cólera-rasgo, cólera-estado, control de la cólera, ansiedadrasgo, ansiedad-estado y la percepción 
de la violencia) considerada como una variable dependiente; también se analiza la acción aislada de cada variable independiente sobre la variable dependiente.

La pertenencia a pandillas escolares (variable independiente) tiene efectos directos sobre las expresiones emocionales vitales y la percepción de la violencia $(\underline{F}=2.117$.05). En el mismo sentido el neuroticismo ejerce influencia sobre la variable dependiente considerada en su conjunto $(\underline{F}=14.500 .05)$.

En la tabla $\mathrm{N}^{\circ} 8$ se presentan los datos derivados del MANOVA. La prueba $\mathrm{F}$ aplicada al análisis del tipo de familia, pertenencia a pandillas escolares y neuroticismo revela diferencias significativas cuando se considera de modo aislado el tipo de familia sobre la percepción de la violencia $(\mathrm{F}=3.862 .05)$.
Figura № 5

\section{Relación entre variables}



El neuroticismo influye sobre cada una de las variables consideradas dentro de cólera-hostilidad a excepción del control de la cólera manifiesta y también sobre ansiedad rasgo-estado y percepción de la violencia. La pertenencia a pandillas también tiene efectos significativos al ,05\% sobre la apreciación de la violencia, pudiéndose observar en la tabla $\mathrm{N}^{\circ} 9$ que la media de este grupo

Tabla № 7

Análisis multivariado (MANOVA) mediante T de Hottelling de FAM $x$ PERT $x$ N y sus interacciones sobre el conjunto de expresiones emocionales y percepción de la violencia

\begin{tabular}{lcrrrr}
\hline & Valor T de Hottelling & F & g.l. de la Hipótesis & g.l. & Significancia \\
\hline FAM & .027 & 1.399 & 18 & 1858 & .121 \\
PERT & .020 & 2.117 & 9 & 930 & $.026^{*}$ \\
$N$ & .422 & 14.500 & 27 & 2786 & $.000^{*}$ \\
FAM x PERT & .015 & 0.788 & 18 & 1858 & .716 \\
FAM x N & .061 & 1.055 & 54 & 5570 & .366 \\
PERT x N & .037 & 1.281 & 27 & 2786 & .151 \\
FAM x PERT x N & .065 & 1.118 & 54 & 5570 & .258 \\
\hline${ }^{*} \mathrm{P}<.05$ & \multicolumn{5}{l}{} \\
FAM = familia & PERT = Pertenencia o no a pandillas
\end{tabular}




\section{Ugarriza}

\section{Tabla № 8}

Efectos entre sujetos. Prueba F aplicada al tipo de familia (FAM): Pertenencia o no a pandillas juveniles (PERT) y neuroticismo (N) sobre las expresiones emocionales vitales y la percepción de la violencia derivados del MANOVA

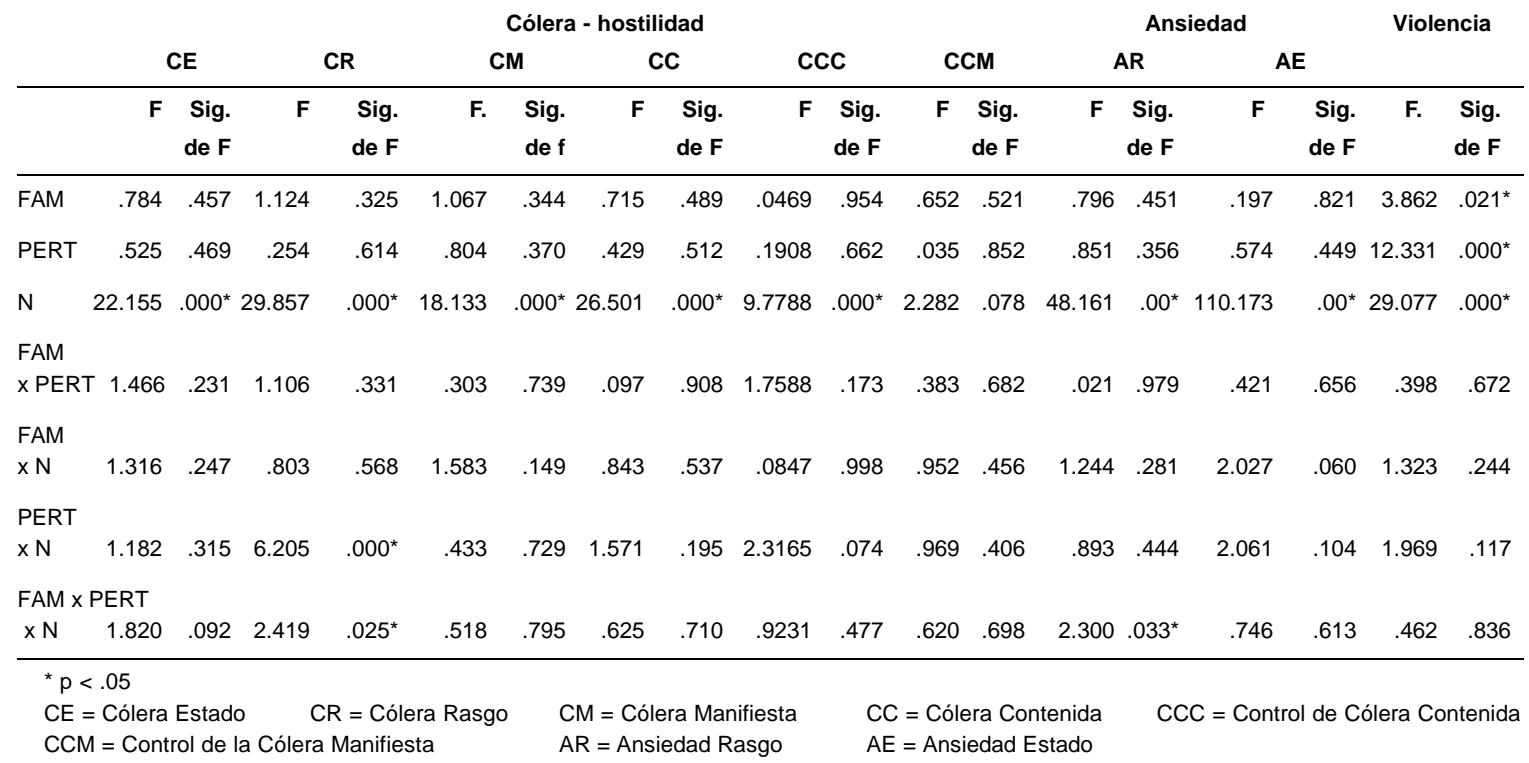

es más elevada que en el grupo que no pertenece a pandillas.

Cuando se examinan las interacciones (véase tabla $\mathrm{N}^{\circ} 8$ ) sólo arrojan valores F significativos al ,05\% la combinación pertenencia a pandillas $\mathrm{x}$ neuroticismo sobre cólera-rasgo. La inter- acción familia $\mathrm{x}$ pertenencia a pandilla $\mathrm{x}$ neuroticismo también influye sobre la misma variable dependiente.

En la tabla $N^{\circ} 10$ se presentan las medias y desviaciones estándares para las diferentes variables dependientes, siendo éstas más elevadas para el grupo al-

Tabla № 9

Medias, desviaciones estándares alcanzadas en las escalas de cólera-hostilidad, ansiedad rasgo-estado y violencia considerando la pertenencia o no a una pandilla

\begin{tabular}{llcccccccccc}
\hline $\begin{array}{l}\text { Pertenece a } \\
\text { Pandilla }\end{array}$ & & CE & CR & CM & CC & CC & CCM & AE & AR & V \\
\hline Sí pertenece & Media & 12.86 & 19.15 & 9.96 & 10.17 & 13.83 & 14.16 & 36.97 & 32.80 & 30.33 \\
$(\mathrm{n}=459)$ & DS & 3.68 & 3.77 & 2.15 & 2.37 & 2.75 & 2.73 & 6.38 & 5.94 & 4.94 \\
& & & & & & & & & & & \\
No pertenece & Media & 12.31 & 18.43 & 9.67 & 9.98 & 13.91 & 14.13 & 36.34 & 32.65 & 28.49 \\
$(\mathrm{n}=503)$ & DS & 3.20 & 3.78 & 2.33 & 2.25 & 2.58 & 2.81 & 5.80 & 5.91 & 4.35 \\
\hline
\end{tabular}


Tabla № 10

Medias, desviaciones estándares alcanzadas en las escalas de cólera-hostilidad, ansiedad rasgo-estado y violencia en relación a las dimensiones estabilidad e inestabilidad emocional (neuroticismo)

\begin{tabular}{|c|c|c|c|c|c|c|c|c|c|c|}
\hline \multirow{2}{*}{$\begin{array}{l}\text { Pertenece a } \\
\text { Pandilla }\end{array}$} & & \multicolumn{6}{|c|}{ Cólera } & \multicolumn{2}{|c|}{ Ansiedad } & \multirow{2}{*}{$\begin{array}{c}\text { Violencia } \\
\text { V }\end{array}$} \\
\hline & & CE & CR & $\mathrm{CM}$ & CC & $\mathrm{CC}$ & $\mathrm{CCM}$ & $\mathrm{AE}$ & AR & \\
\hline \multicolumn{11}{|l|}{ Altamente } \\
\hline \multirow[t]{2}{*}{ Inestable $(n=143)$} & Media & 14.41 & 20.84 & 10.90 & 11.28 & 12.92 & 13.86 & 42.59 & 36.61 & 32.09 \\
\hline & DS & 4.42 & 4.14 & 2.29 & 2.59 & 2.56 & 3.01 & 6.04 & 6.56 & 5.34 \\
\hline \multicolumn{11}{|l|}{ Tendencia } \\
\hline \multirow{2}{*}{ Inestable $(\mathrm{n}=368)$} & Media & 12.94 & 19.50 & 10.11 & 10.54 & 13.58 & 13.92 & 38.15 & 33.89 & 30.02 \\
\hline & DS & 3.68 & 3.53 & 2.27 & 2.24 & 2.74 & 2.75 & 5.31 & 5.80 & 4.63 \\
\hline \multicolumn{11}{|l|}{ Tendencia } \\
\hline \multirow[t]{2}{*}{ Estable $(n=288)$} & Media & 11.91 & 18.15 & 9.34 & 9.53 & 14.25 & 14.37 & 34.99 & 31.30 & 28.32 \\
\hline & DS & 2.67 & 3.42 & 1.79 & 2.03 & 2.37 & 2.71 & 4.46 & 4.78 & 4.10 \\
\hline \multicolumn{11}{|l|}{ Altamente } \\
\hline \multirow[t]{2}{*}{ Estable $(n=163)$} & Media & 11.31 & 16.45 & 8.98 & 8.88 & 14.67 & 14.47 & 31.83 & 29.16 & 27.36 \\
\hline & DS & 2.09 & 3.19 & 2.40 & 1.82 & 2.74 & 2.65 & 4.58 & 4.55 & 3.99 \\
\hline $\mathrm{CE}=$ Cólera Estado & $\mathrm{CR}=\mathrm{C}$ & asgo & $\mathrm{CM}=$ & ra $M$ & iesta & $\mathrm{CC}=$ & era & nida & & \\
\hline $\mathrm{CC}=$ Control de la $\mathrm{C}$ & era Cont & & $\mathrm{CCM}$ & ontrol & la Cóle & Manifie & & & & \\
\hline
\end{tabular}

tamente inestable seguido por el grupo que denota tendencia a la inestabilidad; en cambio las medias son más bajas para el grupo con tendencia a la estabilidad y altamente estables.

Es importante destacar que en la variable dependiente control de la cólera contenida ocurre lo contrario, las medias son más elevadas para los grupos altamente estables y con tendencia a la estabilidad que para los que se ubican dentro del nivel con tendencia al neuroticismo y altamente neuróticos.

En la tabla $\mathrm{N}^{\mathrm{o}} 11$ sólo se presentan las medias y desviaciones estándares para la variable estadísticamente significativa cólera-rasgo (CR). Se observa que las medias para el grupo altamente inestable que pertenecen a pandillas son más elevadas que para las otras combinaciones de pertenencia a pandillas y neuroticismo.

Tabla № 11

Medias desviaciones estándares alcanzadas en cólera rasgo (CR) para las interacciones: pertenencia a pandilla y neuroticismo

\begin{tabular}{|c|c|c|c|c|c|c|}
\hline & \multicolumn{2}{|c|}{ Valor T de Hottelling } & \multirow{2}{*}{$\frac{F}{21.59}$} & \multirow{2}{*}{$\frac{\text { g.I. de la Hipótesis }}{19.72}$} & \multirow{2}{*}{$\frac{\text { g.l. }}{18.06}$} & \multirow{2}{*}{$\frac{\text { Significancia }}{15.98}$} \\
\hline & & $?$ & & & & \\
\hline Pertenencia & sí & $\mathrm{n}$ & 83 & 190 & 135 & 51 \\
\hline$a$ & & DS & 4.19 & 3.36 & 13.11 & 2.86 \\
\hline \multirow[t]{3}{*}{ Pandillas } & & $?$ & 19.80 & 19.26 & 18.23 & 16.66 \\
\hline & NO & $\mathrm{n}$ & 60 & 178 & 153 & 112 \\
\hline & & DS & 3.86 & 3.69 & 3.68 & 3.31 \\
\hline
\end{tabular}


En la tabla $\mathrm{N}^{\mathrm{o}} 12$ se observa que la media más alta, 22,35\% en cólera-rasgo, fue alcanzada por el grupo de jóvenes que calificaron a su familia como extrema, que participan en pandillas escolares y que son neuróticos. Los gráficos de medias marginales de cólera rasgo (figuras 6, 7 y 8) permiten visualizar de modo más claro estos hallazgos.

En la tabla $\mathrm{N}^{\circ} 13$ aparecen las medias y desviaciones estándares alcanzadas en ansiedad-rasgo para las interacciones de las variables consideradas. Las medias más elevadas corresponden a los grupos que perciben a su familia como extrema, que pertenecen a pandillas y que son altamente inestables $(\mathrm{x}=38,88)$ y también para aquéllos que no pertenecen a pandillas, que clasifican a su familia como de rango medio y que denotan tendencia a la inestabilidad $(x=38,90)$. Lo expresado se puede apreciar con mayor nitidez en las figuras 9,10 y 11 , observándose que los valores medios de AR son más elevados en los grupos de adolescentes neuróticos pertenecientes o no a pandillas escolares.

\section{DisCUSIÓN}

Existen diversas explicaciones del porqué el adolescente se involucra en una pandilla y presenta conductas inadecuadas con irrupciones emocionales desordenadas. En un estudio anterior

Tabla № 12

Medias, desviaciones estándares alcanzadas en cólera rasgo (CR) para las interacciones: tipo de familia, pertenencia a pandillas y neuroticismo

\begin{tabular}{|c|c|c|c|c|c|c|c|}
\hline & & \multicolumn{6}{|c|}{ Tipo de Familia } \\
\hline & & \multicolumn{2}{|c|}{ Balanceada } & \multicolumn{2}{|c|}{ Rango Medio } & \multicolumn{2}{|c|}{ Extrema } \\
\hline & & \multicolumn{2}{|c|}{$\begin{array}{l}\text { Pertenencia a } \\
\text { pandillas }\end{array}$} & \multicolumn{2}{|c|}{$\begin{array}{l}\text { Pertenencia a } \\
\text { pandillas }\end{array}$} & \multicolumn{2}{|c|}{$\begin{array}{l}\text { Pertenencia a } \\
\text { pandillas }\end{array}$} \\
\hline & & sí & No & sí & NO & sí & NO \\
\hline \multicolumn{8}{|c|}{ Neuroticismo: } \\
\hline \multirow{3}{*}{$\begin{array}{l}\text { Altamente } \\
\text { inestable }\end{array}$} & $x$ & 21.97 & 19.86 & 20.87 & 21.10 & 22.35 & 17.18 \\
\hline & $\mathrm{n}$ & 32 & 28 & 34 & 21 & 17 & 11 \\
\hline & DS & 4.35 & 3.40 & 4.46 & 3.85 & 3.22 & 4.02 \\
\hline \multirow{3}{*}{$\begin{array}{l}\text { Tendencia } \\
\text { inestable }\end{array}$} & $x$ & 19.97 & 19.45 & 19.61 & 19.07 & 19.00 & 19.04 \\
\hline & $\mathrm{n}$ & 103 & 92 & 61 & 60 & 26 & 26 \\
\hline & DS & 3.34 & 3.86 & 3.48 & 3.45 & 3.17 & 3.74 \\
\hline \multirow{3}{*}{$\begin{array}{l}\text { Tendencia } \\
\text { estable }\end{array}$} & $x$ & 18.12 & 18.14 & 18.02 & 18.04 & 17.96 & 19.17 \\
\hline & $\mathrm{n}$ & 65 & 87 & 45 & 48 & 25 & 18 \\
\hline & DS & 3.14 & 3.39 & 3.33 & 3.79 & 2.73 & 4.72 \\
\hline \multirow{3}{*}{$\begin{array}{l}\text { Altamente } \\
\text { estable }\end{array}$} & $x$ & 16.81 & s16.24 & 16.22 & 17.02 & 13.25 & 17.42 \\
\hline & $\mathrm{n}$ & 29 & 58 & 18 & 42 & 4 & 12 \\
\hline & DS & 3.20 & 3.25 & 2.16 & 3.30 & 1.89 & 3.65 \\
\hline
\end{tabular}


Neuroticismo, expresiones emocionales y percepción de la violencia en escolares

Tabla № 13

Medias, desviaciones estándares alcanzadas en ansiedad rasgo (AR) para las interacciones: tipo de familia, pertenencia a pandillas y neuroticismo

\begin{tabular}{|c|c|c|c|c|c|c|c|}
\hline & & \multicolumn{6}{|c|}{ Tipo de familia } \\
\hline & & \multicolumn{2}{|c|}{ Balanceada } & \multicolumn{2}{|c|}{ Rango medio } & \multicolumn{2}{|c|}{ Extrema } \\
\hline & & \multicolumn{2}{|c|}{$\begin{array}{c}\text { Pertenencia a } \\
\text { pandillas }\end{array}$} & \multicolumn{2}{|c|}{$\begin{array}{c}\text { Pertenencia a } \\
\text { pandillas }\end{array}$} & \multicolumn{2}{|c|}{$\begin{array}{c}\text { Pertenencia a } \\
\text { pandillas }\end{array}$} \\
\hline & & sí & NO & sí & No & sí & No \\
\hline \multicolumn{8}{|c|}{ Neuroticismo: } \\
\hline \multirow{3}{*}{$\begin{array}{l}\text { Altamente } \\
\text { inestable }\end{array}$} & $x$ & 36.50 & 35.61 & 35.56 & 38.90 & 38.88 & 34.82 \\
\hline & $\mathrm{n}$ & 32 & 28 & 34 & 21 & 17 & 11 \\
\hline & DS & 5.18 & 5.98 & 6.94 & 6.81 & 6.60 & 8.92 \\
\hline \multirow{3}{*}{$\begin{array}{l}\text { Tendencia } \\
\text { inestable }\end{array}$} & $x$ & 3.59 & 34.93 & 33.65 & 32.81 & 33.81 & 34.54 \\
\hline & $\mathrm{n}$ & 103 & 92 & 61 & 60 & 26 & 26 \\
\hline & DS & 5.76 & 6.01 & 5.44 & 5.70 & 6.92 & 4.83 \\
\hline \multirow{3}{*}{$\begin{array}{l}\text { Tendencia } \\
\text { estable }\end{array}$} & $x$ & 30.48 & 32.17 & 31.62 & 31.60 & 29.04 & 31.61 \\
\hline & $\mathrm{n}$ & 65 & 87 & 45 & 48 & 25 & 18 \\
\hline & DS & 4.78 & 4.64 & 4.46 & 4.19 & 5.59 & 5.64 \\
\hline \multirow{3}{*}{$\begin{array}{l}\text { Altamente } \\
\text { estable }\end{array}$} & $x$ & 29.76 & 29.55 & 29.22 & 28.86 & 26.00 & 27.83 \\
\hline & $\mathrm{n}$ & 29 & 58 & 18 & 42 & 4 & 12 \\
\hline & DS & 3.48 & 4.83 & 4.31 & 4.66 & 2.94 & 5.78 \\
\hline
\end{tabular}


Figura № 6

Gráfica de medias marginales de cólera rasgo (CR)

Tipo de familia extrema



Figura № 7

Gráfica de medias marginales estimadas de CR

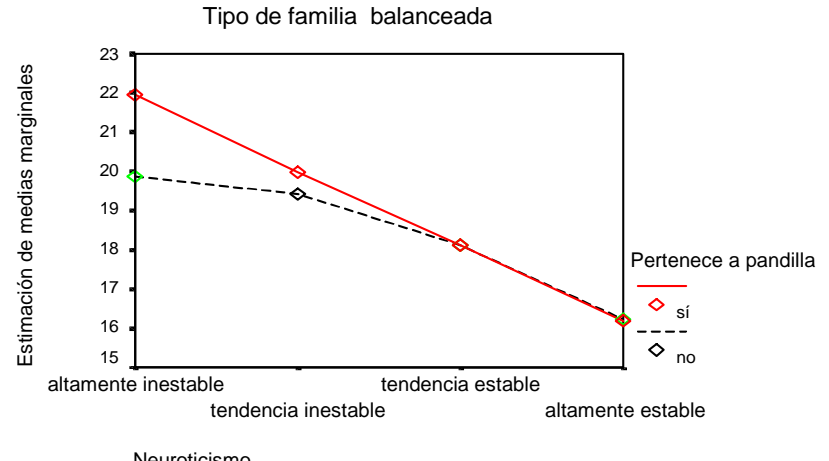

Figura № 8

Gráfica de medias marginales estimadas de CR

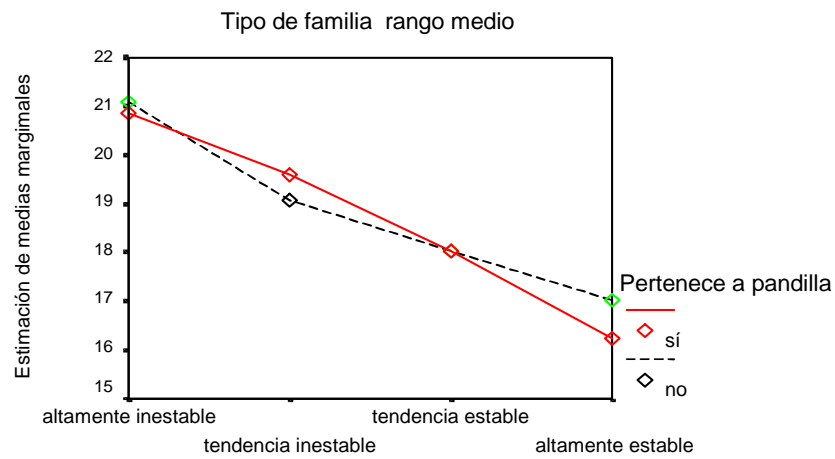

Neuroticismo 
Figura № 9

Gráfica de medias marginales de AR

Tipo de familia extrema

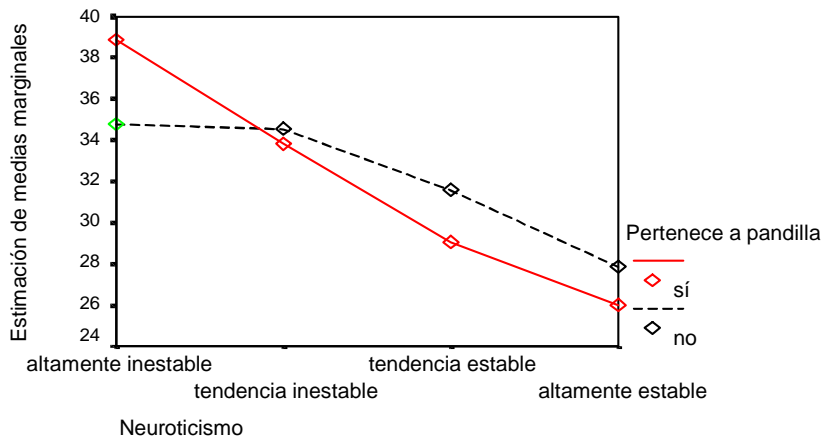

Figura № 10

Gráfica de medias marginales de AR



Figura № 11

\section{Gráfica de medias marginales de AR}

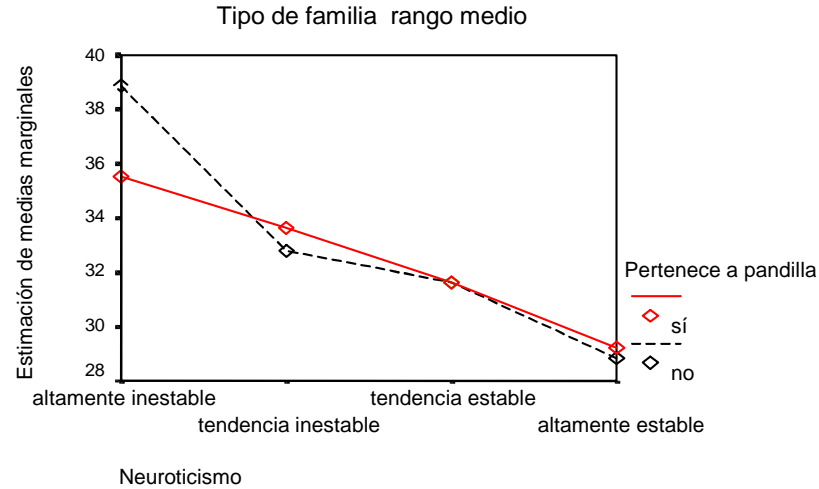


sobre el carácter univariable (Ugarriza, 1988), se examinó que la calidad de la estructura familiar percibida por los adolescentes y la pertenencia a las pandillas escolares no establecía diferencias en la expresión de la cólera-hostilidad, ansiedad y apreciación de la violencia. Se esperaba que la percepción de una familia como extrema, o la interacción entre el tipo de familia y la participación en las pandillas escolares afectarían de modo negativo la expresión de dichas emociones, pero no ocurrió así. Sin embargo, la participación en estos grupos es un factor significativo de las diferencias en cuanto a las manifestaciones de dichos estados emocionales, específicamente la cólera-estado, cólera-rasgo, cólera-temperamento y percepción de la violencia familiar. Un factor no explorado en ese trabajo fue la inestabilidad emocional del adolescente, rasgo de la personalidad que lo hace más proclive a expresar sentimientos de hostilidad, por lo que en el presente trabajo se ha tenido en cuenta el factor neuroticismo como otra variable importante de ser investigada.

A través del análisis multivariable (MANOVA), se ha podido apreciar que la pertenencia a pandillas y el neuroticismo afecta directamente el conjunto de las expresiones emocionales vitales y la percepción de la violencia en el hogar, con los compañeros y frente a las figuras que representan autoridad en la escuela. Este hallazgo permite inferir que la percepción de un sistema familiar disfuncional por parte del adolescente, el modelo que ofrecen los coetáneos con los que comparte "ideales", el sistema escolar dirigido por autoridades que continúan perpetuando la rígida disciplina -impartida por maestros que por sus acciones y disposiciones muchas veces contradicen los valores que ellos mismos preconizan- genera una situación que para el adolescente es caótica y ambigua, que lo induce a buscar refugio en la "pandilla", donde principalmente encuentra la oportunidad de interactuar con otros compañeros de características similares compartiendo sentimientos, emociones y vicisitudes, involucrándose en acciones deplorables como forma de mitigar las frustraciones.

El hogar, la escuela y la comunidad en general, sin proponérselo, se convierten en un semillero que es caldo de cultivo para aquellos adolescentes que por su inmadurez, alta inestabilidad emocional, poca tolerancia a la frustración, dependencia, falta de asertividad y sugestionabilidad van desarrollando una personalidad neurótica susceptible de adoptar patrones de comportamiento reñidos con la moral, sucumbiendo así en actos delictivos reforzados por el medio circundante, formándose una cadena de hábitos consistentes entre sí, y cuando esto ocurre se transforman en rasgos de conducta difíciles de erradicar. La pandilla es un fenómeno social, organizado pero irracional, donde sus 
"líderes" se convierten en modelos a quienes hay que seguir y acatar, porque de lo contrario los adolescentes sienten que pierden su identidad de grupo. El formar parte de pandillas, si bien les genera seguridad, confianza y sentido de pertenencia, la amenaza de estar fuera de ellos (evaluación cognitiva) les causa reacciones emocionales adversas que afectan su salud y su bienestar psicológico promoviendo conductas desadaptativas expresadas en actos delictivos, acatando las normas del grupo, las mismas que se encuentran al margen de cualquier consideración ética.

Este hecho se refleja en los datos encontrados que fueron estudiados mediante el análisis univariable derivado del MANOVA, donde el neuroticismo ejerce efectos significativos en la expresión de cólera-hostilidad, ansiedad rasgo-estado y percepción de las manifestaciones de violencia.

Con base en estos hallazgos se debe realizar investigaciones que aborden un estudio integral del desarrollo de la personalidad, que explore aquellos factores más próximos al adolescente que determinan su participación en grupos delictivos, aun cuando procedan de hogares cuyo sistema familiar es balanceado, es decir, adecuado.

\section{REFERENCIAS}

American Psychiatric Association (1994). Diagnostic and statistic manual of mental disorders, 4a. edición. Washington, DC: APA.

Anicama, J. (1974). Estandarización de la prueba de Eysenck en diferentes sectores poblacionales de Lima. Tesis de bachiller no publicada, Universidad Nacional Mayor de San Marcos, Lima.

Bandura, A. (1973). Aggression: A social learning analysis. Englewood Cliffts, NJ: Prentice-Hall.

Bandura, A. (1977). Social learning theory. Englewood Cliffts, NJ: Prentice-Hall.

Barlow, D. (1988). Anxiety and its disorders. New York: Guilford Press.

Bending, A. (1962). Factor analytic scales of covert and overt hostility. Journal of Consulting Psychology, 26, 200.

Brown, Ch. (1980). Principios de la medición en psicología y educación. México: El Manual Moderno.

Bueno, R. (1998). Validación, confiabilidad entre las escalas de comunicación y satisfacción familiar en estudiantes de una universidad de Lima. Tesis de maestría no publicada, Universidad de San Martín de Porres, Lima.

Busher, J.N. (1995). Clinical personality assessment: Practical approaches. New York: Oxford University Press.

Caine, T., Foulds, G., \& Hope, K. (1967). Manual of the hostility and direction of hostility questionnaire $(H D H Q)$. London: University of London Press.

Cattell, R., y Scheier, I. (1958). The nature of anxiety: a review of thirteen multi- 


\section{Ugarriza}

variate analysis comprising 814 variables. Psychological Reports, 4, 351.

Cruzado, J. (1997), La violencia juvenil. Reflexiones de un día violento en una vida violenta. Primer Concurso de Ensayo Pensando y Haciendo Perú. Lima: Gráfica Bellido.

Eysenck, H. (1971). Estudio científico de la personalidad. Buenos Aires: Paidós.

Gonzales, O. (1991). Muerte en el callejón. Infancia y violencia. Lima: Cedap.

Hernández, A. (1989). Familias no clínicas de Bogotá. Su funcionamiento según el modelo circumplejo de D.H. Olson. Proyecto de investigación. Estructura, marco de referencia, patrones de interacción y psicoterapia de familias urbanas en Colombia. Convenio Ustacolciencias. Bogotá: Colombia.

Jessop, D. (1981). Family relationships as viewed by parents and adolescents: A specification. Journal of Marriage and the Family, 43, 95-107.

Kerlinger, F. (1994). Investigación del comportamiento. México: McGraw-Hill.

Malamud, F. (1987). Un modelo para la descripción familiar: Aplicación del Faces II en el cono norte de Lima. Tesis no publicada, Pontificia Universidad Católica del Perú, Lima.

McGuigan, F. (1994). Entendiendo el estrés y la ansiedad por medio de la psicofisiología. Avances en Psicología Clínica Latinoamericana, 12, 13-21.

Moscoso, M. \& Rehiser, E. (1995). The multicultural spanish inventory of experience of anger: State and trait anger. XXV Congreso Interamericano de Psicología. San Juan de Puerto Rico.
Novaco, R. (1975). Anger control: The development and evaluation of an experimental treatment. Lexington: Lexington Books / DC Heath.

Olson, D., Portner, J., \& Bell, R. (1982). Family inventories used in a national survey of families across the family life cycle. En D. Olson et al., Family adaptability and cohesion evaluation scales (pp. 5-24). St. Paul: University of Minnesota, Family Social Science.

Olson, D., Russell, C., \& Sprenkle, D. (1983). Circumplex model of marital and family systems: VI. Theoretical update. Family Process, 22, 69-83.

Orellana, O. \& García, L. (1996). Violencia y representaciones sociales en escolares. Revista Peruana de Psicología, 1 (1), 26-39.

Pimentel, C. (1986). La violencia en la familia y problemas psicológicos de la barriada. Tesis doctoral no publicada, Universidad Nacional Mayor de San Marcos, Lima.

Pimentel, C. (1995). Violencia, familia y niñez en los sectores urbanos pobres. Lima: Cecosam.

Ponce, S. (1995). Estudio epidemiológico sobre maltrato infantil en población escolarizada de Lima y Callao. Lima: Cedro.

Ráez, C. (1992). Familia y adolescencia: Tipos de familia y modelo ideal familiar, aplicación del cuestionario Faces III en un sector socioeconómico medio de Lima. Tesis no publicada, Unifé, Lima.

Reusche, R. (1994). El modelo circumplejo de funcionamiento familiar en la estructura familiar del adolescente de nivel socioeconómico medio. Un estudio exploratorio en residentes en Lima. Tesis 
de maestría no publicada, UNIFÉ, Lima.

Reusche, R. (1995). Estructura y funcionamiento familiar en un grupo de estudiantes de secundaria de nivel socioeconómico medio alto y bajo rendimiento escolar. Revista de Psicología, 3(3), 163-190. Lima: Unifé.

Reusche, R. (1998). El funcionamiento familiar en el adolescente con problemas de conducta escolar; según la escala para evaluar la adaptación y cohesión de la familia (Faces III) de D.H. Olson. Tesis de doctorado no publicada, Unifé, Lima.

Siegel, S. (1956). The relationship of hostility to authoritarianism. Journal of $A b$ normal and Social Psychology, 52, 368-373.

Spielberger, C. (1972). Anxiety as an emotional state. En C.D. Spielberger (Ed.) Anxiety: Current trends in theory and research. Vol. 1, New York: Academics Press.

Spielberger, C. (1977). Anxiety: theory and research. En B.B. Wolman (Ed.), International Encyclopedia of Psychiatry, Psychology, Psychoanalysis and Neurology. New York: Human Sciences Press.

Spielberger, C. (1980). Preliminary manual for the state-trait anger scale (STAS). Tampa: University of South Florida, Human Resources Institute.

Spielberger, C. (1983). Manual for the state-trait anxiety inventory: STAI (Form Y). Palo Alto: Consulting Psychologists Press.

Spielberger, C. (1988). Manual for the state-trait anger expression inventory (STAXI). Odessa: Psychological Assessment Resources.
Spielberger, C., Jacobs, G. Russell, S., \& Crane, R. (1983). Assessment of anger: The State-Trait Anger Scale (STAS). En J. Butcher \& C.D. Spielberger (Eds.), Advances in personality assessment (Vol. 2. pp. 159-187). Hillsdale, N.J.: Lawrence Erlbaum Associates, Inc.

Spielberger, C., Johnson, E., Russell, S., Crane, R., Jacobs, G. \& Worden, T. (1985). The experience and expression of anger: Construction and validation of an anger and hostility in cardiovascular and behavioral disorders. New York: Hemisphere.

Spielberger, C., \& Moscoso, M. (1995a). La expresión de la cólera y hostilidad y sus consecuencias en el sistema cardiovascular. Revista de Psicología Contemporánea, 2, 32-43.

Spielberger, C., Ritterband, L., Sydemman, S., Reheiser, E. \& Unger, K. (1995b). Clinical Personality Assessment Practical Approaches. En J.N. Butcher.(Ed.), Assessment of emotional states and personality traits: measuring psychological vital signs. New York: Oxford University Press.

Steinberg, L. \& Hill, J. (1978). Patterns of family interaction as a function of age, the onset of puberty and formal thinking. Developmental Psychology, 14(6), 683-684.

Tong, F. (1995). Los jóvenes pandilleros. Lima: Tarea.

Ugarriza, N. (1995). Tipo de familia y comunicación de los adolescentes con sus padres. Theorema, 4(6), 58-60. Lima: Universidad Nacional Mayor de San Marcos.

Ugarriza, N. (1998). Normalización del inventario multicultural de la expresión 


\section{Ugarriza}

de cólera-hostilidad en estudiantes universitarios. Revista de Investigación en Psicología,1(1), 59-88. Lima: Universidad Nacional Mayor de San Marcos.

Ugarriza, N. (en prensa). Ansiedad rasgoestado y expresión de cólera-hostilidad en estudiantes de secundaria de colegios estatales. Lima.

Ugarriza, N. \& Palma, S. (en prensa). Adaptación del inventario de Eysenck, forma adolescentes. Lima.

Ugarriza, N. \& Villanueva, M. (1990). Estudio sobre fármaco-dependencia en grupos vulnerables. Caracas: Instituto Mundo Libre.

Zelin, M.L., Adler, G., \& Myerson, P.G. (1972). Anger self report: An objective questionnaire for the measurement of aggression. Journal of Consulting and Clinical Psychology, 39, 340. 